\title{
Short Communication: Docosahexaenoic Acid Promotes Vaccenic Acid Accumulation in Mixed Ruminal Cultures When Incubated with Linoleic Acid*
}

\author{
A. A. AbuGhazaleh and T. C. Jenkins \\ Department of Animal and Veterinary Sciences, \\ Clemson University, Clemson, SC 29634
}

\section{ABSTRACT}

Previous studies found that feeding dairy cows a blend of fish and soybean oils enhanced milk vaccenic acid (VA) and conjugated linoleic acid (CLA) concentrations more than when the oils were fed separately. In these studies, the authors concluded that a component in fish oil was stimulating ruminal VA production from other sources of unsaturated fatty acids; however, that component was not identified. The objective of this study was to determine whether docosahexaenoic acid (DHA), an omega-3 fatty acid (FA) in fish oil, is the active component that promotes trans-C18:1 FA, VA in particular, accumulation using cultures of mixed ruminal microorganisms. Treatments consisted of control, control plus $5 \mathrm{mg}$ of DHA (DH), control plus $30 \mathrm{mg}$ of soybean oil (SBO), and control plus $5 \mathrm{mg}$ of DHA and $30 \mathrm{mg}$ of SBO (DHSBO). Treatments were incubated in triplicate in $125-\mathrm{mL}$ flasks, and $5 \mathrm{~mL}$ of culture contents was taken at 0 and $24 \mathrm{~h}$ for fatty acid analysis by gasliquid chromatography. After $24 \mathrm{~h}$ of incubation, the level of trans-C18:1 FA (14.1 and $11.7 \mathrm{mg} /$ culture) and VA (13.0 and $10.2 \mathrm{mg} /$ culture) increased more with added DHA than with added SBO, respectively. Combining DHA and SBO yielded higher quantities of transC18:1 FA (21.3 mg/culture) and VA (19.8 mg/culture) in the cultures than either fat source alone. These data suggest that DHA is the component in fish oil that promotes VA accumulation when incubated with linoleic acid.

(Key words: docosahexaenoic acid, soybean oil, vaccenic acid)

Abbreviation key: CLA = conjugated linoleic acid, DH = control plus $5 \mathrm{mg}$ of DHA, DHA = docosahexaenoic acid, DHBSO = control plus $5 \mathrm{mg}$ of DHA and 30

Received July 16, 2003.

Accepted October 10, 2003.

Corresponding author: A. A. AbuGhazaleh; e-mail: aabugha@ clemson.edu.

*Approved as technical contribution number 4935 of the South Carolina Agricultural Experiment Station, Clemson University. mg of SBO, EPA = eicosapentaenoic acid, FA = fatty acid, $\mathbf{S B O}=$ soybean oil, VA $=$ trans -11 vaccenic acid .

Conjugated linoleic acid (CLA) refers to a collection of positional and geometric isomers of octadecadienoic acid with conjugated double bonds. The cis-9, trans-11 CLA is synthesized either in the rumen, as an intermediate in the biohydrogenation of linoleic acid, or in animal tissues by delta-9 desaturase from vaccenic acid (trans-11 C18:1, VA), another intermediate in ruminal biohydrogenation (Griinari and Bauman, 1999). In animal models, cis-9, trans-11 CLA reduced the incidence and growth of tumors, enhanced immune function, and prevented diabetes (Belury, 1995; Parodi, 1997). Recent studies (Corl et al., 2001; Piperova et al., 2002) have indicated that the majority of milk cis-9, trans-11 CLA (78 to 93\%) is derived from delta-9 desaturation of VA. Therefore, Increasing VA production in the rumen would be the most feasible approach to enhancing milk fat cis-9, trans-11 CLA.

Production of VA in the rumen can be enhanced by changes in the diet, especially utilization of diets with greater unsaturated fat content. Previously, researchers (Chouinard et al., 1998; Kelly et al., 1998; Dhiman et al., 2000; Donovan et al., 2000) used soybean oil (SBO), peanut oil, sunflower oil, linseed oil, and fish oil to increase ruminal production of VA and subsequently milk cis-9, trans-11 CLA content. When fed at similar levels, fish oil was more efficient than other polyunsaturated plant oils in increasing milk VA concentration, even though fish oil contains small amounts of the primary precursors (linoleic acid and linolenic acid) of VA (Offer et al., 1999; Whitlock et al., 2002). These findings led AbuGhazaleh et al. (2001) to hypothesize that a component in fish oil may have stimulated ruminal VA production from other sources of unsaturated fatty acids (FA). To test this hypothesis, AbuGhazaleh et al. (2002) fed fish oil from fishmeal with or without extruded soybeans (linoleic acid source) to dairy cows. They observed that feeding the fish meal and extruded soybeans diet gave a greater increase in the concentration of milk cis-9, trans-11 CLA and VA than feeding 
the fish meal or extruded soybeans separately. However, the component in fish oil responsible for the VA increase was not identified (AbuGhazaleh et al., 2002).

Fish oil contains omega-3 FA suspected of playing a role in ruminal trans-C18:1 FA production, in particular VA. The objective of this study was to determine whether docosahexaenoic acid (DHA), an omega-3 FA in fish oil, is the component in fish oil that promotes VA accumulation when incubated with a linoleic acid fat source.

Docosahexaenoic acid was purchased from SigmaAldrich Chemical Company (>99 purity, St. Louis, MO), dissolved in ethanol, and stored at $-5^{\circ} \mathrm{C}$ until used. Whole ruminal content was obtained from a fistulated Holstein cow $2 \mathrm{~h}$ after the morning feeding, strained through 2 layers of cheesecloth, then transported to the laboratory in a sealed container, and used within 20 min. The cow diet was a 55:45 blend of forage (corn silage and alfalfa hay) and concentrate (corn, soybean meal, cotton seeds, minerals, and vitamins). Treatments were (1) control; (2) control plus $5 \mathrm{mg}$ of DHA (DH); (3) control plus $30 \mathrm{mg}$ of soybean oil (SBO); and (4) control plus $5 \mathrm{mg}$ of DHA and $30 \mathrm{mg}$ of SBO (DHSBO). Previous work in our laboratory showed that incubating 5 and $30 \mathrm{mg}$ of DHA and SBO in mixed ruminal cultures, respectively, resulted in the highest trans-C18:1 FA accumulation after $24 \mathrm{~h}$ of incubation (AbuGhazaleh and Jenkins, 2004). Docosahexaenoic acid in $100 \mu \mathrm{L}$ of ethanol was added directly into the $\mathrm{DH}$ and DHSBO cultures. Another $100 \mu \mathrm{L}$ of ethanol was added to the control and SBO cultures for consistency. Soybean oil was mixed with the TMR diet. Cultures were maintained in 125-mL Erlenmeyer flasks containing $500 \mathrm{mg}$ of finely grounded TMR diet, $10 \mathrm{~mL}$ of strained ruminal fluid, $40 \mathrm{~mL}$ of medium, and $2 \mathrm{~mL}$ of reducing solution according to Goering and VanSoest (1970). The diet was a 50:50 blend of forage (corn silage) and concentrate (corn, soybean meal, minerals, and vitamins). Cultures were run in triplicate at $39^{\circ} \mathrm{C}$ under anaerobic conditions. A 5-mL sample was taken from each culture flask at 0 and $24 \mathrm{~h}$, while being stirred with a magnetic bar under a stream of $\mathrm{CO}_{2}$, placed immediately in an ice bath, and then stored at $-5^{\circ} \mathrm{C}$.

Samples were freeze-dried and analyzed for FA by GLC (AbuGhazaleh and Jenkins, 2004). Data were analyzed using the mixed model procedure of SAS (SAS Inst., Inc., Cary, NC) using treatment as the fixed effect and replicate as the random effect. All results were expressed as least square means. Preplanned contrasts were control vs. other treatments, $\mathrm{DH}$ vs. SBO, and DH and SBO vs. DHSBO. Significance was declared at $P$ $<0.05$.

If DHA is the component in fish oil that promotes trans-C18:1 FA accumulation when incubated with

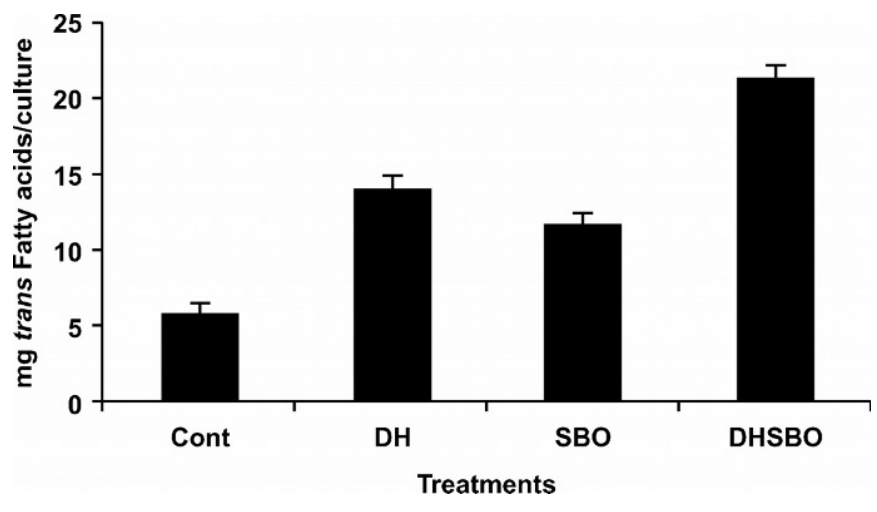

Figure 1. Effect of treatments on milligrams of trans fatty acids in cultures after $24 \mathrm{~h}$ of incubation. Cont $=$ control; $\mathrm{DH}=$ control + $5 \mathrm{mg}$ of docosahexaenoic acid; $\mathrm{SBO}=$ control $+30 \mathrm{mg}$ of soybean oil; DHSBO $=$ control $+5 \mathrm{mg}$ of docosahexaenoic acid $+30 \mathrm{mg}$ of soybean oil.

other unsaturated fat sources, combining DHA with SBO should maximize trans-C18:1 FA level, VA in particular. After $24 \mathrm{~h}$ of incubation, the level of trans-C18:1 FA increased $(P<0.05)$ for all treatments compared with control, and the increase was maximum when DHA and SBO were incubated together (Figure 1). Addition of DHA, SBO, or their mix to ruminal cultures increased trans-C18:1 FA by 142,100 , and $266 \%$, respectively, compared with control. Vaccenic acid level in cultures increased by 158,102 , and $293 \%$ with $\mathrm{DH}$, SBO, and DHSBO treatments, respectively, compared with control. The increase in VA level in cultures with the DHSBO treatment was more than would be predicted by the sum of the DH and SBO treatments (Table 1). The addition of $5 \mathrm{mg}$ of DHA to cultures was more efficient in promoting trans-C18:1 FA accumulation, VA in particular, than $30 \mathrm{mg}$ of SBO. Similar results were reported by AbuGhazaleh et al. (2002) and Whitlock et al. (2002), where the increase in VA level in milk fat was more when a blend of fish oil and extruded soybeans was fed to dairy cows than when fed separately. The highest accumulation of VA with the DHSBO treatment indicates that DHA and/or its derivatives is (are) one of the component(s) in fish oil that promotes VA accumulation when incubated with unsaturated FA provided by other fat sources in the diet (linoleic acid in this experiment).

Although this study clearly shows the role of DHA in promoting VA accumulation, the mechanism is still unknown. The addition of $5 \mathrm{mg}$ of DHA to cultures decreased the disappearance of C18:1 n-9 from 52\% (control and SBO) to 24\% (DH and DHSBO; Table 1). Additionally, after $24 \mathrm{~h}$ of incubation, the level of C18:0 was increased by 129 and $206 \%$ with the control and SBO treatments compared with 13 and $8 \%$ with the DH 
Table 1. Effects of treatments on milligrams fatty acid per culture.

\begin{tabular}{|c|c|c|c|c|c|c|c|c|}
\hline \multirow[b]{2}{*}{ Fatty acid } & \multicolumn{4}{|c|}{ Treatment $^{1}$} & \multirow[b]{2}{*}{$\mathrm{SE}$} & \multicolumn{3}{|c|}{ Contrast $^{2}$} \\
\hline & Cont & $\mathrm{DH}$ & $\mathrm{SBO}$ & DHSBO & & 1 & 2 & 3 \\
\hline & & & & & & $\longrightarrow$ & $-(P)$ & \\
\hline \multicolumn{9}{|l|}{ C18:0 } \\
\hline $0-\mathrm{h}$ & 8.67 & 8.73 & 10.34 & 9.96 & 0.11 & $<0.01$ & $<0.01$ & $<0.01$ \\
\hline 24-h & 19.86 & 9.82 & 31.63 & 10.72 & 0.69 & $<0.01$ & $<0.01$ & $<0.01 \times$ \\
\hline \multicolumn{9}{|l|}{ C18:1 t6-8 } \\
\hline $0-\mathrm{h}$ & $\mathrm{nd}^{3}$ & nd & nd & nd & & & & \\
\hline 24-h & 0.19 & 0.20 & 0.36 & 0.25 & 0.03 & $<0.01$ & $<0.01$ & 0.23 \\
\hline \multicolumn{9}{|l|}{ C18:1 t9 } \\
\hline $0-\mathrm{h}$ & nd & nd & nd & nd & & & & \\
\hline 24-h & 0.27 & 0.40 & 0.47 & 0.55 & 0.05 & $<0.01$ & 0.21 & 0.02 \\
\hline \multicolumn{9}{|c|}{ C18:1t11 vaccenic acid } \\
\hline $0-\mathrm{h}$ & 0.60 & 0.61 & 0.64 & 0.64 & 0.04 & 0.41 & 0.50 & 0.56 \\
\hline 24-h & 5.03 & 12.99 & 10.17 & 19.79 & 0.65 & $<0.01$ & 0.05 & $<0.01$ \\
\hline \multicolumn{9}{|l|}{ C18:1 t12 } \\
\hline $0-\mathrm{h}$ & nd & nd & nd & nd & & & & \\
\hline 24-h & 0.43 & 0.62 & 0.78 & 0.84 & 0.04 & $<0.01$ & 0.01 & 0.01 \\
\hline \multicolumn{9}{|l|}{ C18:1 c9 } \\
\hline $0-\mathrm{h}$ & 7.85 & 8.06 & 13.41 & 13.25 & 0.22 & $<0.01$ & 0.01 & 0.01 \\
\hline 24-h & 3.77 & 6.13 & 6.39 & 10.07 & 0.39 & $<0.01$ & 0.65 & $<0.01$ \\
\hline \multicolumn{9}{|l|}{ C18:2 n-6 } \\
\hline $0-\mathrm{h}$ & 14.16 & 14.07 & 27.29 & 27.05 & 0.53 & $<0.01$ & 0.01 & 0.01 \\
\hline 24-h & 2.87 & 3.15 & 5.1 & 7.31 & 0.47 & $<0.01$ & $<0.01$ & $<0.01$ \\
\hline \multicolumn{9}{|l|}{$\mathrm{CLA}^{4}$} \\
\hline $0-\mathrm{h}$ & nd & nd & nd & nd & & & & \\
\hline $24-\mathrm{h}$ & 0.01 & 0.03 & 0.09 & 0.05 & 0.01 & 0.02 & 0.01 & 0.37 \\
\hline \multicolumn{9}{|l|}{ C18:3 } \\
\hline $0-\mathrm{h}$ & 0.68 & 0.70 & 2.32 & 2.27 & 0.04 & $<0.01$ & $<0.01$ & $<0.01$ \\
\hline $24-\mathrm{h}$ & nd & nd & 0.31 & 0.39 & 0.02 & $<0.01$ & $<0.01$ & 0.68 \\
\hline \multicolumn{9}{|l|}{$\mathrm{DHA}^{5}$} \\
\hline $0-\mathrm{h}$ & nd & 5.54 & nd & 5.48 & 0.05 & $<0.01$ & 0.01 & 0.01 \\
\hline 24-h & nd & 2.29 & nd & 1.77 & 0.10 & $<0.01$ & $<0.01$ & $<0.01$ \\
\hline VA:C18:0 & 0.19 & 1.35 & 0.26 & 1.89 & 0.05 & $<0.01$ & $<0.01$ & $<0.01$ \\
\hline Unsat-lost ${ }^{6}$ & 15.60 & 16.35 & 30.78 & 28.07 & 0.86 & $<0.01$ & $<0.01$ & $<0.01$ \\
\hline VA-gained $^{7}$ & 4.47 & 12.41 & 9.57 & 19.18 & 0.66 & $<0.01$ & 0.02 & $<0.01$ \\
\hline
\end{tabular}

${ }^{1} \mathrm{Cont}=$ control; $\mathrm{DH}=$ control $+5 \mathrm{mg}$ of DHA; SBO = control $+30 \mathrm{mg}$ of soybean oil; DHSBO = control $+5 \mathrm{mg}$ of $\mathrm{DHA}+30 \mathrm{mg}$ of soybean oil.

${ }^{2}$ Contrast 1 (Cont vs. other treatments), 2 (DH vs. SBO), and 3 (DH and SBO vs. DHSBO).

${ }^{3} \mathrm{ND}=$ Not detectable or detected at $<0.01$.

${ }^{4}$ Cis-9, trans-11 conjugated linoleic acid.

${ }^{5} \mathrm{DHA}=$ Docosahexaenoic acid (C22:6).

${ }^{6}$ Unsat-lost $=$ Total C18:1 c9, C18:2 n-6, C18:3, and DHA disappeared after $24 \mathrm{~h}$ of incubation.

${ }^{7}$ VA-gained $=\mathrm{mg}$ VA after $24 \mathrm{~h}$ incubation $-\mathrm{mg}$ VA at $0 \mathrm{~h}$.

and DHSBO treatments, respectively (Table 1). Similar results were observed by AbuGhazaleh and Jenkins (2004) when graded levels of DHA were added to mixed ruminal cultures. The decline in C18:1 n-9 disappearance and C18:0 accumulation from cultures with added DHA led AbuGhazaleh and Jenkins (2004) to conclude that DHA and/or its derivatives may inhibit the reductase enzyme in ruminal microorganisms, which is responsible for the terminal hydrogenation of trans-C18:1 to C18:0 causing the accumulation of trans-C18:1 FA in cultures.

The possibility of other FA in fish oil also being involved in promoting trans-C18:1 FA accumulation can not be ruled out. A good candidate is the other omega3 FA (eicosapentaenoic acid). Addition of eicosapentae- noic acid to mixed ruminal culture also showed a similar effect on the disappearance of C18:1 n-9 and C18:0 accumulations, but to a lesser extent compared with DHA (AbuGhazaleh and Jenkins, 2004). Results from this study show that DHA is the component in fish oil that promotes trans-C18:1 FA accumulation when incubated with a linoleic acid fat source. The addition of small amounts ( $5 \mathrm{mg}$ ) of DHA to mixed ruminal cultures was more effective in promoting VA accumulation than $30 \mathrm{mg}$ of SBO.

\section{REFERENCES}

AbuGhazaleh, A. A., and T. C. Jenkins. 2004. Disappearance of docosahexaenoic and eicosapentaenoic acids from cultures of mixed ruminal microorganisms. J. Dairy Sci. 87:645-651. 
AbuGhazaleh, A. A., D. J. Schingoethe, and A. R. Hippen. 2001. Conjugated linoleic acid and other beneficial fatty acids in milk fat from cows fed soybean and/or fish meals. J. Dairy Sci. 84:1845-1850.

AbuGhazaleh, A. A., D. J. Schingoethe, A. R. Hippen, and L. A. Whitlock. 2002. Feeding fish meal and extruded soybeans enhances the conjugated linoleic acid (CLA) content of milk. J. Dairy Sci. 85:624-631.

Belury, M. A. 1995. Conjugated dienoic linoleate: A polyunsaturated fatty acid with unique chemoprotective properties. Nutr. Rev. $53: 83-89$.

Corl, B. A., L. H. Baumgard, D. A. Dwyer, J. M. Griinari, B. S. Phillips, and D. E. Bauman. 2001. The role of (9-desaturase in the production of cis-9, trans-11 CLA. J. Nutr. Biochem. 12:622-630.

Dhiman, T. R., L. D. Satter, M. W. Pariza, M. P. Galli, K. Albright, and M. X. Tolosa. 2000. Conjugated linoleic acid (CLA) content of milk from cows offered diets rich in linoleic and linolenic acid. J. Dairy Sci. 83:1016-1027.

Donovan, C. D., D. J. Schingoethe, R. J. Baer, J. Ryali, A. R. Hippen, and S. T. Franklin. 2000. Influence of dietary fish oil on conjugated linoleic acid and other fatty acids in milk fat from lactating dairy cows. J. Dairy Sci. 83:2620-2628.

Goering, H. K., and P. J. Van Soest. 1970. Forage fiber analysis (apparatus, reagents, procedures, and some applications). Agric. Handbook No. 379. ARS-USDA, Washington, DC.
Griinari, J. M., and D. E. Bauman. 1999. Biosynthesis of conjugated linoleic acid and its incorporation into meat and milk in ruminants. Pages 180-200 in Recent Advances in Conjugated Linoleic Acid Research. M. P. Yurawecs, M. M. Mossoba, J. K. G. Kramer, G. Nelson and M. W. Pariza, ed. AOCS Press, Champaign, IL.

Kelly, M. L., J. R. Berry, D. A. Dwyer, J. M. Griinari, P. Y. Chouinard, M. E. Van Amburgh, and D. E. Bauman. 1998. Dietary fatty acid sources effect conjugated linoleic acid (CLA) concentrations in milk from lactating dairy cows. J. Nutr. 128:881-885.

Offer, N. W., M. Marsden, J. Dixon, B. K. Speake, and F. E. Thacker. 1999. Effect of dietary fat supplements on levels of n-3 polyunsaturated fatty acids, trans acids and conjugated linoleic acid in bovine milk. Anim. Sci. 69:613-625.

Parodi, P. W. 1997. Cow's milk fat components as potential anticarcinogenic agents. J. Nutr. 127:1055-1060.

Piperova, L. S., J. Sampugna, B. B. Teter, K. F. Kalscheur, M. P. Yurawecz, Y. Ku, K. M. Morehouse, and R. A. Erdman. 2002. Duodenal and milk trans octadecenoic acid and conjugated linoleic acid (CLA) isomers indicate that postabsorpative synthesis is the predominant source of cis-9-containing CLA in lactating dairy cows. J. Nutr. 132:1235-1241.

Whitlock, L., D. J. Schingoethe, A. R. Hippen, R. J. Baer, N. Ramaswamy, and K. M. Kasperson. 2002. Fish oil and extruded soybeans fed in combination increase CLA in milk of dairy cows more than when fed separately. J. Dairy Sci. 85:234-243. 